\title{
Activin-A stimulates hypothalamic gonadotropin-releasing hormone release by the explanted male rat hypothalamus: interaction with inhibin and androgens
}

\author{
A E Calogero, N Burrello, A M Ossino, P Polosa and R D'Agata \\ Division of Andrology, Department of Internal Medicine, University of Catania, 95123 Catania, Italy \\ (Requests for offprints should be addressed to A E Calogero, Istituto di Medicina Interna e Specialità Internistiche, Ospedale Garibaldi, Piazza S.M. di Gesù, \\ 95123 Catania, Italy)
}

\begin{abstract}
The presence of activins in those hypothalamic regions containing gonadotropin-releasing hormone $(\mathrm{GnRH})$ secreting neurons suggests that these peptides may regulate the reproductive function modulating not only pituitary FSH release and biosynthesis, but also hypothalamic GnRH release. The purpose of this study was to evaluate the effects of activin-A, a homodimer of inhibin $\beta_{\mathrm{A}}$ subunit, on hypothalamic GnRH release in vitro and, because of their well known antithetical effects, to evaluate its interaction with inhibin. In addition, since androgens modulate the release of $\mathrm{GnRH}$ from male rat hypothalami, we thought it of interest to study the possible interplay between these steroids and activin on GnRH release. To accomplish this, we employed a hypothalamic organ culture system which enabled us to evaluate GnRH release from individually incubated hemi-hypothalami explanted from male rats. Activin-A stimulated GnRH release in a biphasic manner. The maximal effect was reached at a concentration of $10 \mathrm{ng} / \mathrm{ml}$ which increased $\mathrm{GnRH}$ output by about 75\%. Inhibin abolished the stimulatory effect of a maximally effective concentration of activin-A in a dose-dependent manner, whereas alone it
\end{abstract}

had no effect on GnRH output. As previously shown, testosterone $(1 \mathrm{nmol} / \mathrm{l})$ and dihydrotestosterone (DHT, $0 \cdot 1 \mathrm{nmol} / \mathrm{l}$ ) suppressed basal $\mathrm{GnRH}$ release, but only testosterone was able to inhibit the release of $\mathrm{GnRH}$ stimulated by activin-A. Since DHT is a non-aromatizable androgen, we evaluated whether the inhibitory effect of testosterone was due to its in vitro conversion into $17 \beta$ estradiol. The addition of 4-hydroxyandrostenedione, a steroidal aromatase inhibitor, did not influence the suppressive effect of testosterone on $\mathrm{GnRH}$ release stimulated by activin-A.

In conclusion, activin-A stimulated hypothalamic GnRH release in vitro and this effect was abolished by inhibin and was blunted by testosterone. These findings suggest that activins may participate in the regulation of the hypothalamic-pituitary-gonadal axis by modulating $\mathrm{GnRH}$ release. The ability of testosterone to suppress the release of $\mathrm{GnRH}$ stimulated by activin-A indicates that this steroid has a potent negative feedback influence on GnRH release.

Journal of Endocrinology (1998) 156, 269-274

\section{Introduction}

Activins and inhibins are dimer glycoproteins sharing a common $\beta$-subunit. Inhibin is a heterodimer of an inhibin-specific $\alpha$-subunit and one of the two closely related $\beta$-subunits $\left(\beta_{\mathrm{A}}\right.$ or $\left.\beta_{\mathrm{B}}\right)$, thus forming two different inhibins: inhibin- $A$ and inhibin-B. Activins originate from the dimerization of two $\beta$-subunits. Hence, they exist in three different molecular forms: activin-A, a homodimer of the $\beta_{\mathrm{A}}$ subunit, activin- $\mathrm{B}$, a homodimer of the $\beta_{\mathrm{B}}$ subunit, and activin-AB, a heterodimer (see Ying 1988 for review).

Activins and inhibins were initially identified for their capability to stimulate and inhibit, respectively, the release of pituitary follicle-stimulating hormone (FSH) (Ling et al.
1985, 1986, Rivier et al. 1985, Vale et al. 1986). Although these glycoproteins were first isolated from the gonads, they were since found to be widely distributed (Meunier et al. 1988) and it was hypothesized that they may also act on the hypothalamus indirectly to regulate FSH secretion (Franchimont et al. 1989). The presence of $\beta_{\mathrm{A}}$ and $\beta_{\mathrm{B}}$ subunit-containing neurons in the septal and preoptic regions of the hypothalamus, where gonadotropinreleasing hormone $(\mathrm{GnRH})$-containing neurons are mainly located, suggests that activins may participate in the regulation of GnRH release (Vale et al. 1988). More recently, the activin receptor ActRII has been found expressed in several hypothalamic areas involved in neuroendocrine regulation, such as the suprachiasmatic, supraoptic, paraventricular, and arcuate nuclei (Cameron 
et al. 1994), adding further circumstantial evidence for a possible physiological role of activins at the hypothalamic level. These observations prompted us to examine the effects of activin-A on GnRH release by employing a hypothalamic organ culture system which enabled us to study GnRH release from individually incubated hemihypothalami explanted from male rats. Given that activins and inhibins exert antithetical effects (Ying 1988), we evaluated their interaction on GnRH release. Moreover, based on the observation that testosterone and its $5 \alpha$ reduced derivative dihydrotestosterone (DHT) suppress GnRH release (Calogero et al. 1993), we also examined whether these androgens may modulate the effects of activin-A on $\mathrm{GnRH}$ release in vitro.

\section{Materials and Methods}

\section{Materials}

Human recombinant activin-A was generously donated by Genentech Inc. (South San Francisco, CA, USA). Bovine inhibin was purchased from Peninsula Laboratories Europe Ltd (St Helens, Merseyside, UK). Testosterone and DHT were purchased from Sigma Chimica (Milan, Italy). 4-Hydroxyandrostenedione (4OH-A, CGP-31349) was a gift from Ciba-Geigy S.p.A. (Origgio, VA, Italy). ${ }^{125} \mathrm{I}-$ Labeled GnRH was purchased from New England Nuclear (Boston, MA, USA). Steroids were solubilized in absolute ethanol and the highest concentration of ethanol used in the tissue culture was $0 \cdot 01 \%$. At this concentration, ethanol did not have any detectable effect on GnRH release (data not shown).

\section{Removal and incubation of hypothalami}

Experiments were performed using intact male SpragueDawley rats weighing 200-225 g (8-9 weeks old) (Charles River, Calco, CO, Italy). Animals were housed for 4-5 days in a temperature-controlled room $\left(22^{\circ} \mathrm{C}\right)$ with lights on from 0700 to $1900 \mathrm{~h}$. Rat chow and tap water were available ad libitum. The rats were killed by decapitation and hypothalami explanted and halved longitudinally as previously reported (Calogero et al. 1993). The hemihypothalami (one tissue per well, 48-multiwell plates; Costar, Cambridge, MA, USA) were placed in a waterjacketed incubator at $37^{\circ} \mathrm{C}$ under an atmosphere of $95 \%$ air and $5 \% \mathrm{CO}_{2}$. Preincubation and incubation were carried out using medium-199 with modified Earle's salt (Gibco, Paisley, Strathclyde, UK) containing $0 \cdot 1 \%$ bovine serum albumin (fraction V; Sigma) and $20 \mu \mathrm{mol} / \mathrm{l}$ bacitracin (zinc salt, Aldrich, Milwaukee, WI, USA) (M199).

\section{Experimental protocols}

The hemi-hypothalami were preincubated for $30 \mathrm{~min}$ in M199 before the experiments were run. The experimental design consisted of 2 passages of the hemi-hypothalami into different wells (one hemi-hypothalamus $/ 0.5 \mathrm{ml}$ ) every $6 \mathrm{~h}$ (total length of the experiment $12 \mathrm{~h}$ ). This interval of incubation was selected on the basis of preliminary studies which showed that activin-A had no effect after $45 \mathrm{~min}$ and $2 \mathrm{~h}$ of incubation (data not shown), but was fully effective after $6 \mathrm{~h}$. Tissue transfer from one well to the other was carried out with a $3 \times 3 \mathrm{~mm}$ nylon mesh grid (nylon monofilament $44 \mu$; Small Parts, Miami, FL, USA). In the second well, a number of hemi-hypothalami for each experiment were exposed to a depolarizing concentration $(60 \mathrm{mmol} / \mathrm{l})$ of potassium chloride $(\mathrm{KCl})$ to test tissue viability by identifying the GnRH response. Three different protocols were used in this study.

Protocol 1 was designed to evaluate the effects of activin-A, inhibin, testosterone and DHT upon unstimulated GnRH release. For this purpose, each hemihypothalamus was incubated in M199 without test substance in the first well (the concentration of GnRH was used as basal $\mathrm{GnRH}$ release for that given tissue) and exposed to graded concentrations of activin-A or inhibin and to $1 \mathrm{nmol} / 1$ testosterone or $0.1 \mathrm{nmol} / 1 \mathrm{DHT}$ in the second well (treated GnRH release). The effects of the zero concentration of activin-A, inhibin, testosterone, and DHT were evaluated by incubating the hemihypothalami with M199 alone also in the second well.

Protocol 2 was designed to evaluate the effects of inhibin, testosterone, and DHT on activin-A (10 ng/ml)stimulated GnRH release. For this purpose, the hemihypothalami were incubated in M199 without test substance in the first well (basal GnRH release) and exposed to graded concentrations of inhibin plus activin-A, testosterone (1 nmol/l) plus activin-A or DHT $(0 \cdot 1 \mathrm{nmol} / \mathrm{l})$ plus activin-A in the second well (treated GnRH release). The effect of activin-A alone was determined by incubating the hemi-hypothalami allocated to this treatment in M199 containing $10 \mathrm{ng} / \mathrm{ml}$ activin-A in the second well.

Protocol 3 was designed to evaluate the effect of 4OH-A on testosterone-suppressed, activin-A-stimulated GnRH release. For this purpose, the hemi-hypothalami were incubated in M199 alone in the first well (basal $\mathrm{GnRH}$ release) and incubated with activin-A $(10 \mathrm{ng} / \mathrm{ml})$ alone, activin-A $(10 \mathrm{ng} / \mathrm{ml})$ plus testosterone $(1 \mathrm{nmol} / \mathrm{l})$ or activin-A $(10 \mathrm{ng} / \mathrm{ml})$ plus testosterone $(1 \mathrm{nmol} / \mathrm{l})$ plus 4-OH-A $(1 \mu \mathrm{mol} / \mathrm{l})$ in the second well (treated GnRH release).

\section{$\mathrm{Gn} R \mathrm{H}$ radioimmunoassay}

The concentration of GnRH in the incubation medium was measured by RIA as previously reported (Calogero et al. 1993). Standard solutions and medium samples were measured in duplicate. GnRH antiserum, used at a final dilution of 1:15000, bound $40 \cdot 8 \pm 1.9 \% \quad(n=14)$ ${ }^{125} \mathrm{I}-\mathrm{GnRH} \quad(\approx 3200$ c.p.m.). Nonspecific binding was 

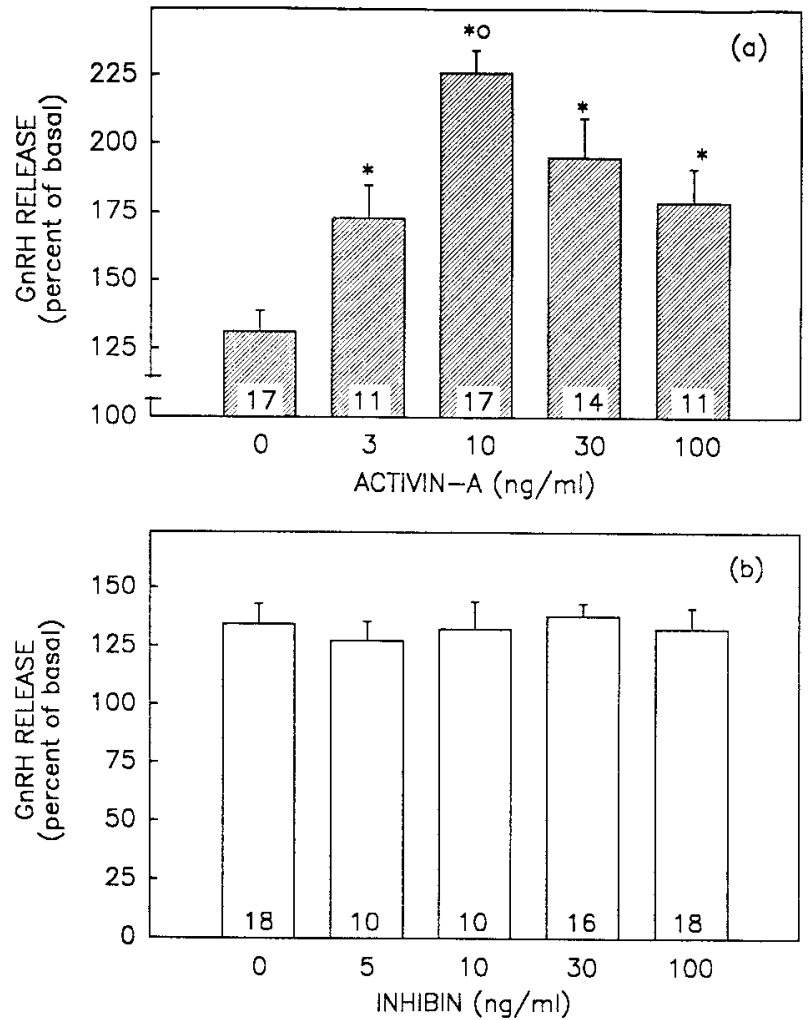

Figure 1 Effects of (a) activin-A and (b) inhibin on hypothalamic $\mathrm{GnRH}$ release. The results (means \pm S.E.M.) were calculated as percentage of basal GnRH release from each individual hemi-hypothalamus. The number of tissues tested is shown within the bars. ${ }^{*} P<0.05$ vs zero concentration; ${ }^{\circ} P<0.05$ vs all other activin-A concentrations.

$1 \cdot 98 \pm 0 \cdot 11 \%$. The sensitivity $\left(\mathrm{ED}_{90}\right)$ of the assay was $4 \cdot 64 \pm 0.28 \mathrm{pg} / \mathrm{ml}(1 \cdot 16 \pm 0.07 \mathrm{pg} /$ well $)$. The intra-assay and interassay coefficients of variation were $2 \cdot 8 \pm 0 \cdot 2 \%$ and $10 \cdot 3 \%$ respectively.

\section{Analysis of data}

The results (means \pm s.E.M.) were calculated as percentage of basal GnRH release from each tissue applying the following formula: $\mathrm{GnRH}(\%)=$ treated $\mathrm{GnRH}$ release divided by basal GnRH release multiplied by 100 . Statistical evaluation was performed by one-way analysis of variance (ANOVA) followed by Duncan's multiple range test. Significance was accepted at a $P$ value lower than 0.05.

\section{Results}

The mean ( \pm s.E.M.) GnRH basal release during the first $6 \mathrm{~h}$ of incubation was $11 \cdot 3 \pm 1 \cdot 4 \mathrm{pg} /$ well, whereas the release of $\mathrm{GnRH}$ during the second $6 \mathrm{~h}$ of incubation in M199 alone was $13.9 \pm 1.5 \mathrm{pg} /$ well $(133.5 \pm 4.9 \%$ of

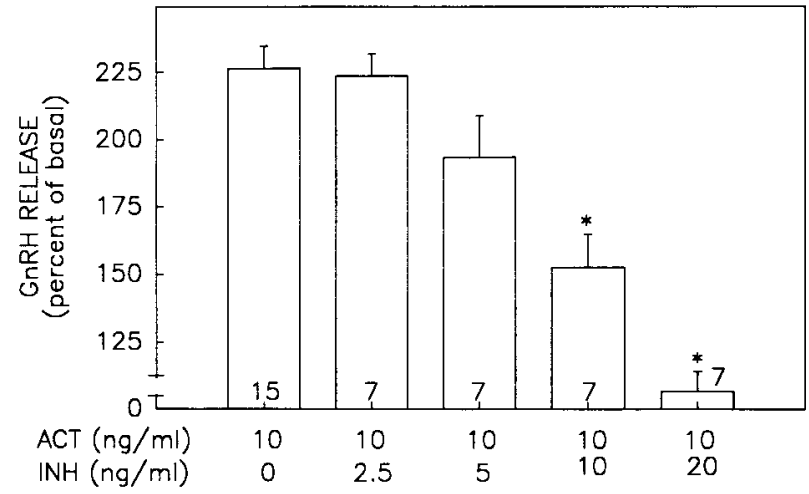

Figure 2 Effects of increasing concentrations of inhibin (INH) on hypothalamic GnRH release stimulated by activin-A (ACT). The results (means \pm S.E.M.) were calculated as percentage of basal $\mathrm{GnRH}$ release from each individual hemi-hypothalamus. The number of tissues tested is shown within the bars. ${ }^{*} P<0.05$ vs activin-A alone.

basal). Those hemi-hypothalami which were exposed to $60 \mathrm{mmol} / 1 \mathrm{KCl}$ in the second well increased their $\mathrm{GnRH}$ output by $362 \cdot 4 \pm 15 \cdot 3 \%$ of basal. This effect disappeared in the presence of the calcium channel blocker verapamil $(10 \mu \mathrm{mol} / \mathrm{l})$, suggesting that $\mathrm{KCl}$-induced $\mathrm{GnRH}$ release was calcium-dependent (data not shown). Activin-A stimulated hypothalamic GnRH release in a biphasic manner (Fig. 1a). The greatest effect was achieved at $10 \mathrm{ng} / \mathrm{ml}$ (5 ng/well) when GnRH output was increased by about $75 \%$. Activin-A was less effective at higher concentrations. Given the antithetical effects of activin and inhibin, we tested whether the latter had any effect on activin-A-stimulated GnRH release. The results of these experiments showed that inhibin suppressed, dosedependently, the release of GnRH stimulated by a maximally effective concentration of activin-A (Fig. 2). The lowest effective concentration of inhibin was $10 \mathrm{ng} / \mathrm{ml}$ which reduced $\mathrm{GnRH}$ release by about 35\%. At a higher concentration $(20 \mathrm{ng} / \mathrm{ml})$, inhibin suppressed completely the stimulatory effect of activin-A. Inhibin did not have any effect upon unstimulated GnRH release (Fig. 1b).

Because of the reported inhibitory effect of testosterone and DHT on hypothalamic GnRH release (Calogero et al. 1993), we tested whether these androgens were able to modulate the effects of activin-A on GnRH release. Testosterone, at a concentration of $1 \mathrm{nmol} / \mathrm{l}$, suppressed both unstimulated and activin-A $(10 \mathrm{ng} / \mathrm{ml})$-stimulated GnRH release (Fig. 3, open bars). On the other hand, DHT, at a concentration of $0 \cdot 1 \mathrm{nmol} / \mathrm{l}$, suppressed unstimulated, but not activin-A-stimulated GnRH release (Fig. 3, solid bars). We also evaluated whether inhibition of aromatase activity would have any consequence on the inhibitory effect of testosterone. The addition of 4OH-A, a steroidal aromatase inhibitor, did not influence the suppressive effect of testosterone on GnRH release stimulated by activin-A (Fig. 4). 


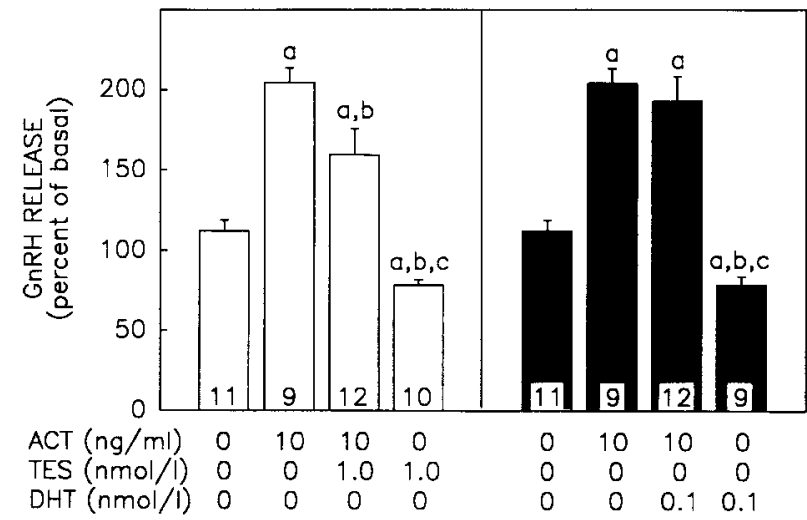

Figure 3 Effects of testosterone (TES, open bars) or dihydrotestosterone (DHT, solid bars) on basal and activin-A (ACT)-stimulated hypothalamic $\mathrm{GnRH}$ release. The results (means \pm S.E.M.) were calculated as percentage of basal GnRH release from each individual hemi-hypothalamus. The number of tissues tested is shown within the bars. ${ }^{a} P<0.05$ vs control (ACT 0 , TES 0, DHT 0); ${ }^{\mathrm{b}} P<0.05$ vs activin-A alone; ${ }^{\mathrm{c}} P<0.05$ vs activin-A plus TES or DHT.

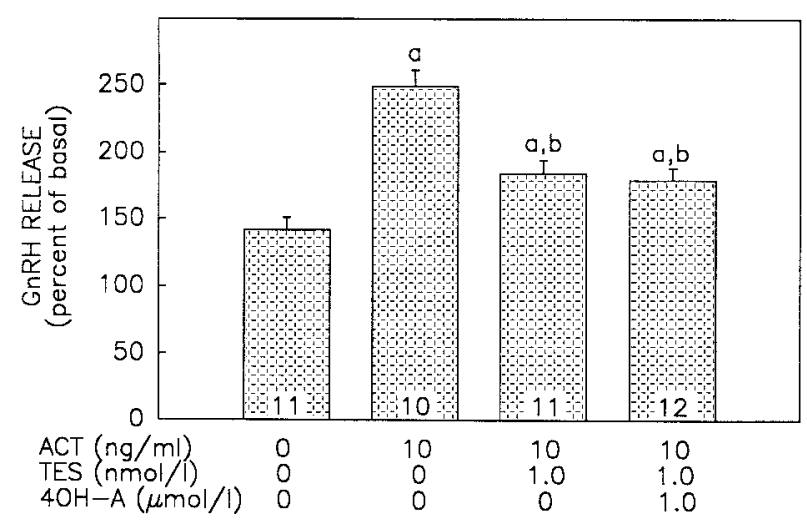

Figure 4 Effects of 4-hydroxyandrostenedione $(4 \mathrm{OH}-\mathrm{A})$, a steroidal aromatase inhibitor, on activin-A (ACT)-stimulated hypothalamic $\mathrm{GnRH}$ release suppressed by testosterone (TES). The results (means \pm S.E.M.) were calculated as percentage of basal GnRH release from each individual hemi-hypothalamus. The number of tissues tested is shown within the bars. ${ }^{a} P<0.05$ vs control (ACT 0 , TES 0, DHT 0); ${ }^{b} P<0.05$ vs activin-A alone.

\section{Discussion}

The effects of activin on pituitary FSH biosynthesis and release are well known (see Ying 1988 for review). Activin-A produces a dose-dependent release of FSH and a parallel increment of the FSH $\beta$-subunit mRNA from pituitary cell cultures. This effect is completely overridden by inhibin and takes at least $4 \mathrm{~h}$ to become evident. No effect is detected on luteinizing hormone ( $\mathrm{LH})$ release and on LH $\alpha$ - and $\beta$-subunit mRNA expression (Carroll et al. 1989, Corrigan et al. 1991). In addition, activin potentiates the effects of $\mathrm{GnRH}$ on FSH, but not $\mathrm{LH}$, release (Ling et al. 1986, Vale et al. 1986). A monoclonal antibody against activin- $\mathrm{B}$, added to a primary culture of anteropituitary cells, decreases FSH release and FSH $\beta$-subunit mRNA expression, suggesting that activin may play an autocrine role in the regulation of FSH release (Corrigan et al. 1991). Activin is also able to increase FSH serum levels in the whole animal with a maximal serum FSH increment observed after $4 \mathrm{~h}$ (Carroll et al. 1991, Doi et al. 1991, Rivier \& Vale 1991). Previous administration of $\mathrm{GnRH}$ antagonists does not prevent the stimulatory effect of activin-A, whereas inhibin reverses it (Rivier \& Vale 1991). Interestingly, activin-A is devoid of effect on FSH release and biosynthesis in immature and ovariectomized female rats, but becomes fully effective after $17 \beta$-estradiol $\left(\mathrm{E}_{2}\right)$ replacement therapy (Carroll et al. 1991).

In addition to a pituitary site of action, effects of activins and inhibins on the release and/or biosynthesis of hypothalamic $\mathrm{GnRH}$ release have been suggested (Lumpkin et al. 1981, Condon et al. 1983, Greef et al. 1983). The recent demonstration that $\beta$-subunits and the activin receptor ActRII mRNA are present in hypothalamic regions involved in the release of GnRH provided the neuroanatomical basis for a possible effect of activins on $\mathrm{GnRH}$ release and/or biosynthesis (Vale et al. 1988, Cameron et al. 1994). Accordingly, Gonzalez-Manchion and co-workers (1991) found that activin-A is able to stimulate, in a concentration- and time-dependent fashion, the release of GnRH from the GnRH-secreting cell line GT1-7. The maximal effect (50\% stimulation) was achieved after two days of incubation with activin-A and was partially suppressed (by about 30\%) by the co-incubation with inhibin. Interestingly, the secretory effect of activin-A was accompanied by a change in the cellular morphology to a more neuronal phenotype. Our findings, obtained from an experimental model employing a tissue with a preserved structure, confirmed that activin-A is able to stimulate $\mathrm{GnRH}$ release. However, in contrast to the study employing the GT1-7 cell line (Gonzalez-Manchion et al. 1991), the maximal effect attained was stronger, it was obtained at a lower concentration (i.e. $10 \mathrm{vs} 20 \mathrm{ng} / \mathrm{ml}$ ), and it required only $6 \mathrm{~h}$ of incubation to became evident. In addition, inhibin was able to overcome completely the stimulation induced by activin-A. The preserved tissue integrity of our hypothalamic explants (Calogero et al. 1989) may explain the more pronounced effects of activin and inhibin described in this study. This has been proven true for the pituitary gland, since intact hemi-pituitaries exhibit a greater hormonal responsiveness than dispersed pituitary cells (Milenkovic et al. 1989). Despite early studies suggesting a hypothalamic site of inhibin action (Lumpkin et al. 1981, Condon et al. 1983, Greef et al. 1983), we and others (Gonzalez-Manchion et al. 1991, Knight 1996) have been unable to find any effect of inhibin on basal GnRH release. This finding may support the hypothesis that the main site of inhibin action is the pituitary (Tilbrook et al. 1993).

Gonadal steroids play a relevant role in the functional activity of the hypothalamic GnRH-secreting neuron. 
Indeed, it has been suggested that the negative feedback action of testosterone is mainly exerted on the release of hypothalamic GnRH (Plant 1986, Tilbrook et al. 1993). We reported that this steroid suppresses GnRH release in a dose-dependent manner (Calogero et al. 1993). The finding that testosterone also suppressed the effects of activin-A on GnRH release indicates a more extensive negative feedback influence. The observation that GnRH neurons apparently lack steroid receptors (Huang \& Harlan 1993) raises the question whether the effects of testosterone are mediated by other interneuronal pathways, although recent work has challenged this tenet (Poletti et al. 1994). The interaction between testosterone and activin-A has also been studied using FSH release from primary cultures of pituitary cells. In this experimental model, testosterone augmented basal and activin-Astimulated FSH release and suppressed the potentiation between activin-A and GnRH (Miyake et al. 1994).

Since several laboratories have reported elevation in LH serum levels after the administration of aromatase inhibitors or antiestrogens (reviewed in Plant 1986), it has been hypothesized that the negative feedback of testosterone on $\mathrm{GnRH}$ is mediated by its conversion into $\mathrm{E}_{2}$. Indeed, hypothalamic neurons have the biosynthetic machinery to operate this conversion (see Plant 1986 for review). Since the nonaromatizable androgen DHT did not modulate activin-A-stimulated GnRH release, we tested the hypothesis that the effects of testosterone could be due to its conversion to $E_{2}$. However, inhibition of aromatase activity did not influence the effects of testosterone on activin-A-stimulated $\mathrm{GnRH}$ release, suggesting that the negative feedback was mediated by testosterone itself. This finding was not completely unexpected since nonaromatizable androgens, such as DHT, are as effective as testosterone in slowing down LH pulse frequency in vivo (reviewed in Plant 1986) and in suppressing hypothalamic GnRH release in vitro (Calogero et al. 1993). In addition, we have been unable to detect any effect of $E_{2}$ on hypothalamic $\mathrm{GnRH}$ release from the explanted male rat hypothalamus (Calogero et al. 1993).

In conclusion, this study showed that activin-A stimulates hypothalamic $\mathrm{GnRH}$ release and that this effect was overridden by inhibin and, in part, by testosterone. This effect of testosterone does not seem to relate to its possible in vitro aromatization into $\mathrm{E}_{2}$. We speculate that activins may modulate the hypothalamic-pituitary-gonadal axis by acting also at the hypothalamic level and the presence of these proteins in the central nervous system regions involved in the release of $\mathrm{GnRH}$ assign them a paracrine modulating role.

\section{Acknowledgements}

This study was supported in part by a grant from MURST, Fellowship in Internal Medicine.

\section{References}

Calogero AE, Bernardini R, Margioris AN, Bagdy G, Gallucci WT, Munson PJ, Tamarkin L, Tomai TP, Brady L, Gold PW \& Chrousos GP 1989 Effects of serotonergic agonists and antagonists on corticotropin-releasing hormone secretion by explanted rat hypothalami. Peptides 10 189-200.

Calogero AE, Weber RFA \& D'Agata R 1993 Effects of rat prolactin on gonadotropin-releasing hormone secretion by the explanted male rat hypothalamus. Neuroendocrinology 57 152-158.

Cameron VA, Nishimura E, Mathews LS, Lewis KA, Sawchenko PE \& Vale WW 1994 Hybridization histochemical localization of activin receptor subtypes in rat brain, pituitary, ovary, and testis. Endocrinology 134 799-808.

Carroll RS, Corrigan AZ, Gharib SD, Vale W \& Chin WW 1989 Inhibin, activin, and follistatin: regulation of follicle-stimulating hormone messenger ribonucleic acid levels. Molecular Endocrinology 3 1969-1976.

Carroll RS, Kowash PM, Lofgren JA, Schwall RH \& Chin WW 1991 In vivo regulation of FSH synthesis by inhibin and activin. Endocrinology 129 3299-3304.

Condon TP, Leipheimer RE \& Curry JJ 1983 Preliminary evidence for a CNS site of action of ovarian inhibin. Life Sciences $\mathbf{3 2}$ 1691-1698.

Corrigan AZ, Bilezikjian LM, Carroll RS, Bald LN, Schmelzer CH, Frendly BM, Mason AJ, Chin WW, Schwall RH \& Vale W 1991 Evidence for an autocrine role of activin B within rat anterior pituitary cultures. Endocrinology 128 1682-1684.

Doi M, Igarashi M, Hasegawa Y, Eto Y, Shibai H, Miura T \& Ibuki Y 1991 In vivo action of activin-A on pituitary-gonadal system. Endocrinology 130 139-144.

Franchimont P, Hazee-Hagelstein MT, Jaspar JM, Charlet-Renard C \& Demoulin A 1989 Inhibin and related peptides: mechanisms of action and regulation of secretion. Journal of Steroid Biochemistry 32 193-197.

Gonzalez-Manchion C, Bilezikjian LM, Corrigan AZ, Mellon PL \& Vale W 1991 Activin-A modulates gonadotropin-releasing hormone secretion from a gonadotropin-releasing hormone-secreting neuronal cell line. Neuroendocrinology 54 373-377.

de Greef WJ, de Jong FH, de Koning J, Steenbergen J \& van der Vaart PDM 1983 Studies on the mechanism of the selective suppression of plasma levels of follicle-stimulating hormone in the female rat after administration of steroid-free bovine follicular fluid. Journal of Endocrinology 97 327-338.

Huang X \& Harlan RE 1993 Absence of androgen receptors in LHRH immunoreactive neurons. Brain Research 624 309-311.

Knight PG 1996 Roles of inhibins, activins, and follistatins in the female reproductive system. Frontier in Neuroendocrinology 17 476-509.

Ling N, Ying S-Y, Ueno N, Esch F, Denoroy L \& Guillemin R 1985 Isolation and partial characterization of a $M_{\mathrm{r}} 32000$ protein with inhibin activity from porcine follicular fluid. Proceedings of the National Academy of Sciences of the USA 82 7217-7221.

Ling N, Ying S-Y, Ueno N, Shimasaki S, Esch F, Hotta M \& Guillemin R 1986 Pituitary FSH is released by a heterodimer of the $\beta$-subunits from the two forms of inhibin. Nature $\mathbf{3 2 1}$ 779-782.

Lumpkin M, Negro-Vilar A, Franchimont P \& McCann S 1981 Evidence for a hypothalamic site of action of inhibin to suppress FSH release. Endocrinology 108 1101-1104.

Meunier H, Rivier C, Evans RM \& Vale W 1988 Gonadal and extragonadal expression of inhibin $\alpha, \beta_{\mathrm{A}}$ and $\beta_{\mathrm{B}}$ subunits in various tissues predicts diverse functions. Proceedings of the National Academy of Sciences of the USA 85 247-251.

Milenkovic L, Rettori V, Snyder GD, Beutler B \& McCann SM 1989 Cachectin alters anterior pituitary hormone release by a direct action in vitro. Proceedings of the National Academy of Sciences of the USA $862418-2422$. 
Miyake T, Irahara M, Shitukawa K, Yasui T \& Aono T 1994 Interaction of activin $\mathrm{A}$ and gonadal steroids on $\mathrm{FSH}$ secretion from primary cultured rat anterior pituitary cells. Biochemical and Biophysical Research Communications 194 413-419.

Plant TM 1986 Gonadal regulation of hypothalamic gonadotropinreleasing hormone release in primates. Endocrine Reviews 7 75-88.

Poletti A, Melcangi RC, Negri-Cesi P, Maggi R \& Martini L 1994 Steroid binding and metabolism in the luteinizing hormonereleasing hormone-producing neuronal cell line GT1-1. Endocrinology 135 2623-2358.

Rivier C \& Vale W 1991 Effect of recombinant activin-A on gonadotropin secretion in the female rat. Endocrinology 129 2463-2465.

Rivier J, Spiess J, McClintock R, Vaughan J \& Vale W 1985 Purification and partial characterization of inhibin from porcine follicular fluid. Biochemical and Biophysical Research Communications $133120-127$.

Tilbrook AJ, de Kretser DM \& Clarke IJ 1993 Human recombinant inhibin-A and testosterone act directly at the pituitary to suppress plasma concentrations of FSH in castrated rams. Journal of Endocrinology 138 181-189.

Vale W, Rivier J, Vaughan J, McClintock R, Corrigan A, Woo W, Karr D \& Spiess J 1986 Purification and characterization of a FSH releasing protein from porcine ovarian follicular fluid. Nature 321 776-779.

Vale W, Rivier C, Hsueh A, Campen C, Meunier H, Bicsak T, Vaughan J, Corrigan A, Bardin W, Sawchenko P, Petraglia F, Yu J, Plotsky P, Spiess J \& Rivier J 1988 Chemical and biological characterization of the inhibin family of protein hormones. Recent Progress in Hormone Research 44 1-34.

Ying S-Y 1988 Inhibins, activins, and follistatins: gonadal proteins modulating the secretion of follicle-stimulating hormone. Endocrine Reviews 9 267-293.

Received 10 March 1997

Revised manuscript received 30 June 1997

Accepted 18 September 1997 